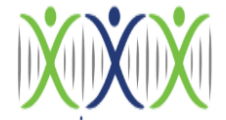

iRASD
Pakistan Journal of Humanities and Social Sciences

Volume 9, Number 3, 2021, Pages 317-327

Journal Homepage:

https://journals.internationalrasd.org/index.php/pjhss

\title{
An Analysis of Service Provision Standards in Primary Health Care Facilities of Khyber Pakhtunkhwa, Pakistan
}

\author{
Rizwan Khurshid $^{1}$, Malik Fahim Bashir ${ }^{2}$, Yasir Bin Tariq ${ }^{3}$ \\ ${ }^{1}$ Department of Management Sciences, COMSATS University Islamabad, Virtual Campus \\ Email: rizwan.khurshid1@gmail.com \\ ${ }^{2}$ Assistant Professor, Department of Management Sciences, Abbottabad Campus, Khyber Pakhtunkhwa, Pakistan. \\ Email: malik.fah@gmail.com \\ ${ }^{3}$ Assistant Professor, Department of Management Sciences, Abbottabad Campus, Khyber Pakhtunkhwa, Pakistan. \\ Email: yasirbintariq@gmail.com
}

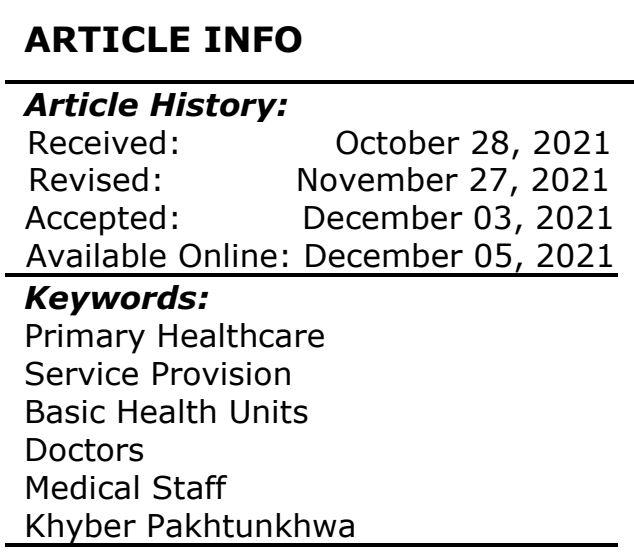

\section{ABSTRACT}

This study explores the on-ground facilities available at primary healthcare facilities (PHCFs) against the service quality standards set by the provincial government of Khyber Pakhtunkhwa (KP), Pakistan. Primary data through a structured questionnaire was collected from 109 PHCFs. Two hundred seven responses from patients, 109 responses from PHCFs doctors and medical staff, and 109 researcher's observations were recorded. Most service provision standards were met in rural health centres (RHCs) and basic health units (BHUs). However, the situation at civil dispensaries (CDs) was very alarming. Patients preferred RHCs on BHUs and CDs because of relatively better quality services provided in RHCs. However, in general, patients prefer to go to secondary or tertiary health care facilities due to the number of reasons identified by this study. Among the areas which demand quality improvement include cultural constraints, lack of following standard operating procedures (SOPs) for referral, no transport facility to referred patients, higher waiting time for patients, and no or fewer health education sessions, and unavailability of cold chain and waste disposal system. By addressing problem areas identified by this study, the KP government can reduce the patient burden on secondary and tertiary health facilities. As a result, service quality at PHCFs will improve access to primary health care, a world health organization's millennium development goal, and the united nations' sustainable development goal.

(C) 2021 The Authors, Published by iRASD. This is an Open Access Article under the Creative Common Attribution Non-Commercial 4.0

Corresponding Author's Email: yasirbintariq@gmail.com

\section{Introduction}

Primary Healthcare (PHC) is the first point of contact an individual has with the healthcare system in a country. Primary health care plays an essential part in reducing the patient burden on secondary and tertiary healthcare facilities. PHC makes universal healthcare accessible to communities, families, and individuals. Moreover, it impacts economic progress, as healthy nations live longer and are more creative and productive, directly affecting their economic growth. Health is a part of the United Nation's Sustainable Development Goals (SDGs) and the World Health Organization's (WHO) Millennium Development Goals (MDGs), which emphasize, among others, the need for quality primary health care.

Pakistan has a three-tiered health delivery system (see Table 1). Primary healthcare services are provided through rural healthcare centres (RHCs), basic health units (BHUs), and civil dispensaries (CDs). Adding more to it, Mother \& Child Healthcare Centers, TB centres \& leprosy clinics play a supportive and selective role towards primary healthcare. CDs are available for a small town or area to cope with their need for basic health services. 
Similarly, BHUs are constructed to cover one union council, which has a catchment population of 25,000 . Likewise, RHC covers a catchment population of 100,000 people. RHCs include preventive, diagnostic, and indoor services as well. Pakistan has a three-tier health system explained in Table 1.

Table 1: Pakistan's Health Care System

\begin{tabular}{cll}
\hline \multicolumn{1}{c}{ Level } & & \multicolumn{1}{c}{ Service Providing Units } \\
\hline & $\bullet$ & Rural Healthcare Centers (RHCs) \\
Primary & $\bullet$ & Basic Health Units (BHUs) \\
& - & Civil Dispensaries (CDs) \\
Secondary & - & Tehsil Headquarters \\
Tertiary & - & District Headquarter \\
\hline
\end{tabular}

Source: Developed by authors

In the constitution of Pakistan, the provision of health services is the responsibility of the provincial government. The government of Khyber Pakhtunkhwa has set specific standards under Improving Quality of Healthcare Services (IQHCS) in 2010[1]. These primary healthcare standards are also assessment tools for quality measurement. Primary healthcare quality is measured according to the set standards for Primary Healthcare Facilities (PHCFs). Primary healthcare standards consist of two major sections

- Service Management

- Service Provision

Service management standards are related to managing human resources, equipment, health record, basic utilities (electricity, drinking water, toilets), and grievance redress. Service provision is related to the services which are provided in PHCFs. This includes accessibility of services, emergency services to patients, the privacy of patients, diagnosis of diseases, child's health, health education, and rational prescription of drugs, cold chain management, and disposal system. This research study is focused on service provision by analyzing the quality of services provided in primary healthcare centres in Khyber Pakhtunkhwa. Particularly, this research study has the following objectives.

- To identify the areas demanding quality improvement in terms of service provision.

- To assess patients' satisfaction regarding services availed at the government's primary healthcare centres.

The importance of this research work cannot be neglected because the current study is the pioneering work carried out in Khyber Pakhtunkhwa, which assessed the standards of services in PHCFs. Outcomes of this study can be beneficial in the following ways. First, policymakers can target weaker aspects at the ground level affecting the quality of services. Second, stakeholders can decide future reforms/steps for the betterment of PHCs services. Third, because of the improvement in the quality of primary healthcare services, patients' burden on secondary and tertiary care facilities will lessen.

\section{Literature Review}

Previous Literature on primary health majorly focuses on reasons for neonatal and infant mortality in Pakistan. Few studies focused the service provision in primary health care facilities. Nizar and Chagani (2016) compared the health care delivery system of Pakistan and Singapore. They concluded that monitoring and evaluation play an important role in improving health outcomes and ensuring the access and continuity of primary health care. Shabbir et al. (2016) analyzed the relationship between healthcare perceived service quality and patient loyalty. Yohana et al. (2016) researched the policy documents and guidelines as a reference for primary healthcare performance. Policy documents and guidelines set as a standard by World Health Organization play a vital role in understanding the diseases and help the services providers (Doctors) to diagnose the patients according to that policy.

\footnotetext{
${ }^{1}$ healthkp.gov.pk/public/uploads/downloads-200.pdf
} 
A study was conducted in Nigeria by Ugo et al. (2016) to assess challenges faced before and after providing technical government support and to document the successes and challenges encountered for quality improvement in primary healthcare facilities. Belintxon et al. (2020) looked into the challenges faced by parents from diverse cultures and nurses in primary health care. Russell et al. (2021) explored rural women's maternity experiences at primary health care centers in Australia. Mohammed et al. (2016) focused on patients' perceptions regarding the perceived health care services delivered to them. Ten indicators were identified, which are communication access, decision making, provider knowledge and skills, physical environment, patients' education, electro-medical record, pain control, discharge process, and preventive services. Patients' experiences regarding the healthcare services in the ten factors mentioned above help shape their perception of primary healthcare facilities. Zheng et al. (2013) studied the effect of increased investment on health reforms in China.

Worthington and Gogne (2011) conducted a study in India to understand the social and cultural factor's impact on patients' satisfaction. In primary healthcare, social and cultural factors negatively impact patients' well-being. Suphanchaimat et al. (2015) studied the healthcare mechanism for migrants to explore migrants' perception of healthcare quality. It was revealed that service providers face a challenge in managing the migrants due to language and cultural barriers. Similarly, Alhassan et al. (2015) determined the difference in perception of patients and staff on health care quality.

Mečev and Goleš (2015) examined patients' perceptions regarding the quality of services in Sibenik city. The aim was to check whether there was any difference between patient expectations and satisfaction with medical services. Halcomb et al. (2020) explored the challenges faced by the medical staff of the PHCFs in Australia during the COVID-19 pandemic. Martin-Iguacel et al. (2019) highlighted the importance of PHCFs in the early detection of an HIV infection.

Quality is an ongoing process, and it demands to be monitored continuously. Studies discussed in this literature review measured the quality of PHC from different dimensions. However, to the best of the researcher's knowledge, no such research has been done before, which assessed the set standards of service provision for primary healthcare in Pakistan.

\section{Materials and Methods}

The population of this research study is primary healthcare facilities, i.e., civil dispensaries (CDs), basic health units (BHUs), and rural health centres (RHCs) of Khyber Pakhtunkhwa (KP). There are $447 \mathrm{CDs}, 784$ BHUs, and 111 RHC in the whole KP province. Primary healthcare facilities (CDs, BHUs and RHCs) of district Mansehra were taken as a sample because it has the highest number of primary healthcare facilities in KP and was manageable within the cost and time constraints of this study. Of the whole KP province, District Mansehra has $13.42 \%$ of CDs, $6.37 \%$ of BHUs, and $8.10 \%$ of RHCs.

There was a total of sixty CDs, fifty BHUs, and nine RHCs in district Mansehra. Ten CDs were non-functional due to lack of human resource or land mutation issues, so responses were only collected from the functional healthcare facilities of district Mansehra. Data was collected through a questionnaire designed on two scales (Likert and Dichotomous) as per the nature of the questions. The questionnaire was comprised of three portions, Primary health facilities staff-related portion, patients-related portion, and researcher's observation portion.

Staff portion was filled by doctors and medical technicians or dispensers available at PHCFs. The patients' portion was filled by the patient and was guided by the researcher throughout the filling process. The researcher filled the personal observation portion by personally observing the required parameters. A total of 109 responses from staff and 207 responses from patients were obtained. Furthermore, 109 personal observations were made. Data collected was then entered in SPSS for analysis and were analyzed separately for each portion. 


\section{4.}

\section{Result and Discussion}

Data were analyzed using simple descriptive statistics to get a clear picture of areas demanding quality improvement. A total of hundred and nine 109 PHCFs (50 CDs, 50 BHUs, and 9 RHCs) were studied. A simple descriptive analysis of data was made on 109 staff's responses, 207 responses from patients, and 109 personal observations. The standards set by the Khyber Pakhtunkhwa government (in bold) and the measurable criteria (in italic) against which the performance of 109 PHCFs was measured are given in appendix 1 . The following section contains the analysis and discussion of the data collected against each service quality standard.

\section{Standard 2.1: The Facility and the services provided are easy and accessible to the catchment area population}

As per Standard 2.1, healthcare facilities should lie within the $5 \mathrm{Km}$ range of the catchment population. Table 2 shows that most healthcare facilities lie within the catchment population. Furthermore, respondents highlighted cultural constraints as an obstacle to service provision. A total of 138 responses ( 77 from CDs, 47 from BHUs, and 14 from RHCs) were received. These responses revealed different kinds of constraints faced by patients in PHCFs of Khyber Pakhtunkhwa. The distribution of constraints from all PHCFs is as follows. Fifty-one responses were about religious needs (Parda), 12 responses were about tribal restrictions, 42 responses came regarding family restrictions, and 28 responses were about other miscellaneous issues faced by patients. This analysis shows that most of the constraints were at the CD level.

Regarding the community's needs (patients) in a PHC facility, $90 \%$ of responses revealed that patients' needs were fulfilled in BHUs and RHCs. In CDs, minimal services were provided, and there was no female staff in 48 out of $50 \mathrm{CDs}$. Thus, female patients weren't provided with the required medical care at the CD level. A total of 63 out of 87 responses from CDs, 65 out of 93 responses from BHUs, and 23 out of 27 responses from RHCs revealed that the attitude of staff is friendly. Seventeen responses were about a non-friendly attitude. This shows that the attitude of the staff working in primary healthcare facilities is overall very friendly except few.

Table 2: Accessibility and constraints to patient

\begin{tabular}{|c|c|c|c|c|c|c|}
\hline \multirow{2}{*}{ Measurable Criteria } & \multicolumn{2}{|c|}{ Civil Dispensary } & \multicolumn{2}{|c|}{ Basic Health Unit } & \multicolumn{2}{|c|}{ Rural Health Center } \\
\hline & Yes & No & Yes & No & Yes & No \\
\hline $\begin{array}{l}\text { Facility is located within } \\
5 \mathrm{Km} \text { of catchment area }\end{array}$ & $98.90 \%$ & $1.10 \%$ & $90.30 \%$ & $9.70 \%$ & $96.20 \%$ & $3.70 \%$ \\
\hline
\end{tabular}

Source: Based on Authors' data analysis

\section{Standard 2.2: A list of available services and applicable fees is posted where the clients/patients can see them}

Working hour's chart informs a patient about the service window. During this research study, it was observed that 3 out of $50 \mathrm{CDs}$, 49 out of 50 BHUs, and 7 out of 9 RHCs have displayed working hours' chart/poster. Emergency numbers are very important in any emergency to contact the concerned authorities/departments. Only 2 out of $50 \mathrm{CDs}, 24$ out of 50 BHUs, and 6 out of 9 RHCs have emergency phone numbers displayed in the facilities. According to standards, the community and patients should be aware of services provided in the facility. The list of services includes details of services provided in PHCFs. The list of services charts was displayed in only 1 out of $50 \mathrm{CDs}, 24$ out of 50 BHUs, and 6 out of 9 RHCs. It was also observed that most of the patients were unaware of the services available at these healthcare centres.

\section{Standard 2.3: Clients/Patients and their attendants are received in a friendly and respectful manner irrespective of their sex, age, race, religion or physical appearance}

Regarding standard 2.3, 12 out of 87 responses from CDs, 12 out of 93 responses from BHUs, and 6 out of 27 responses from RHCs revealed that medical staff investigated the patients in detail and asked questions about their disease. According to service standards, the diagnosis should be explained to the patients. Apart from 2 responses from BHUs, all the 
responses from PHCFs expressed that patients were informed about the diagnoses. Overall, this standard is achieved in all the PHCFs of district Mansehra.

According to PHC standards, the service provider should explain the care management to patients. The 40 (45) responses from CDs, 38 (54) responses from BHUs, and 13 (14) responses from RHCs expressed that patients were frequently (rarely) explained about care management by the staff. Two responses from CDs and one response from BHUs claimed that patients were never explained about care management. Furthermore, the PHC standards also suggest that service providers should ask the patients for follow-up visits. The 39 (44) responses from CDs, 30 (60) from BHUs, and 12 (15) from RHCs revealed that patients were frequently asked (rarely asked) for follow-up visits. Only four responses from CDs and three from BHUs revealed that patients were not asked for follow-ups. This result indicates the lack of asking for follow-up practice at the CDs and BHUs level.

Similarly, PHC standards suggest that staff should deal with the patients in a kind and polite manner. A friendly hospital environment affects patients' perceptions positively. Regarding medical personnel attitude, 59 (15) [13] responses from CDs, 48 (13) [32] responses from BHUs and 20 (4) [3] responses from RHCs revealed about the friendly (neutral) [non-friendly] attitude of the doctors, medical technicians, and dispensers. Apart from a few BHUs, this standard was achieved in most of the PHCFs of district Mansehra.

Additionally, by listening properly to patients, the service providers can easily understand the history regarding the patient's disease, which effectively helps to diagnose and cure the illness. Regarding listening, 67 (8) responses from CDs, 49 (14) responses from BHUs and 22 (2) responses from RHCs revealed that staff listens (do not listen) to patients properly. The overall result indicates that patients in district Mansehra are satisfied with the attention paid by the doctor and medical technicians during the consultation. Furthermore, 49 (22) [6] responses from CDs, 41(46) [6] from BHUs and 12 (15) responses from RHCs show that patient feedback is taken frequently (rarely) [never]. Overall, this standard was achieved in most of PHCFs.

\section{Standard 2.4: Providers give priority to extremely sick clients/patients and those of extreme age (early newborns and elderly)}

According to standard 2.4, patients should be treated as per their arrival time. Almost full responses from CDs (99\%), BHUs (94\%) and RHCs (96.3\%) showed that patients are treated as per their arrival. Moreover, $97 \%$ of responses from CDs, $88 \%$ from BHUs, and $89 \%$ from RHCs showed that aged patients are given priority over the normal routine patients. As per standards, severely ill patients should be given priority over the rest of the patients. A majority of responses from CDs (91\%), BHUs (82\%), and RHCs (96\%) revealed that severely sick patients were given priority over normal routine patients. This standard is achieved in all the PHCFs of district Mansehra.

\section{Standard 2.5: Providers use a defined process for referring emergency cases}

According to PHC standards, staff should know the Standard Operating Procedure (SOP) for the referral. Only $38 \%$ of the staff in CDs understands the SOPs for a referral. Compared to CDs, $84 \%$ of the BHUs staff knows the SOPs regarding referral. Similarly, the staff of 6 out of 9 RHCs knows SOPs of referral. The rest of the 3 RHC staff refer patients, but they do not know the SOPs for the referral. Likewise, the referral form should give adequate information to the attending staff for the continuity of care. After checking the referral slips/ outpatient department (OPD) slip on which patients were referred from 109 PHCFs, it was observed that $38 \%$ of the staff in 109 functional PHCFs does not write sufficient information regarding the referral of patients, which do not allow the proper continuity of care for the attending staff (where the patient was referred).

Table 3: Proper referral systems known and followed

\begin{tabular}{lcccccc}
\hline \multirow{2}{*}{ Measurable Criteria } & \multicolumn{2}{c}{ Civil Dispensary } & \multicolumn{2}{c}{ Basic Health Unit } & \multicolumn{2}{c}{ Rural Health Center } \\
\cline { 2 - 7 } & Yes & No & Yes & No & Yes & No \\
\hline Staff know SOP of referral & $38 \%$ & $62 \%$ & $70 \%$ & $30 \%$ & $66.70 \%$ & $33.30 \%$ \\
Info in Referral form & $48 \%$ & $52 \%$ & $78 \%$ & $22 \%$ & $55.6 \%$ & $44.40 \%$ \\
Transport for patients & $0 \%$ & $100 \%$ & $2 \%$ & $98 \%$ & $77.8 \%$ & $22.20 \%$ \\
Record of Referral & $56 \%$ & $44 \%$ & $72 \%$ & $28 \%$ & $88.9 \%$ & $11.10 \%$ \\
\hline
\end{tabular}


Similarly, there is no transportation available for the patients in CDs. Only 1 in 50 BHUs has an ambulance, whereas 7 out of 9 RHCs have ambulances available to transport patients to the referred facility or the nearest possible secondary or tertiary level hospital. Additionally, a copy/record of the referral should be kept in the facility. This research observed that in 72 out of 109 PHCFs ( 28 CDs, 36 BHUs, and 8 RHCs), a copy/record of referral is kept in the referral register. The facilities where the referral register was available maintained the record according to the referral register. The rest of the facilities recorded the information such as referred patient name, reason of referral, age, and address of patients in the OPD register.

Furthermore, apart from the listed services, staff should provide possible assistance to the patients. It was asked from staff in PHCFs regarding some extra assistance to patients. The staff of 27 PHCFs ( $10 \mathrm{CDs}$ and $17 \mathrm{BHU}$ ) claimed to make a phone call to the referred facility and tell them the condition of patients so that the receiving facility could make the necessary arrangements. The staff in 18 PHCFs (6 CDs, 11 BHUs, and 1 RHC) arranged a community ambulance for the patients. The staff of 56 PHCFs (34 CDs, 21 BHUs, and 2 RHCs) reported that they provide some minor assistance to the patients regarding the address of the referred facility, name of the referred hospital, nearest available service, fee for any private checkup, and carriage of the patient on stretcher or wheelchair up to the ambulance.

\section{Standard 2.6: Non-Priority clients/patients wait no more than one hour after arrival at the facility before being seen by the provider}

Almost all responses from CDs (99\%), BHUs (94\%), and RHCs $(96 \%)$ revealed that patients were treated as per their arrival time. The staff of 81 PHCFs ( 35 CDs, 39 BHUs, and 7 RHCs) analyzed patients' waiting time and took precautionary steps to minimize the waiting time.

\section{Standard 2.7: The privacy of patients/clients is ensured during consultation and examination}

The data reveals that the issue of patients' privacy was very severe in CDs as there were no screens/curtains available for female privacy. In the case of BHUs, it was observed that apart from 4 BHUs, all other 46 BHUs have somehow arranged for the patients' privacy. All the 9 RHCs have an arrangement for patients' privacy which is an excellent sign, and this is why patients prefer to go to RHC as compared to $\mathrm{CD}$ or BHU. This standard needs improvement at the CDs level.

\section{Standard 2.8: All clients/Patients receive appropriate assessment, diagnosis, plan of care, treatment and care management, and follow-up}

During this study, three basic assessments in PHCFs for adults (temperature, blood pressure, and symptom identification) were assessed. The majority of healthcare facilities (95\% responses) have basic assessments for adults. Few exceptional cases were reported where BP apparatus and thermometer were non-functional or broken. This standard was achieved in PHCFs of district Mansehra. Similarly, for children, it was observed that only 3 out of $50 \mathrm{CDs}$ weighed the child patients (less than five years), and 13 CDs administered immunization. Weight machines and Ice-Line Refrigerators (ILRs) were not available in most of the CDs. In some cases, weight machines were available but were non-functional; this standard was not achieved in CDs of district Mansehra.

As per KP PHC standards, patient history should be taken, which helps any other service provider understand the condition and causes of the disease. In 3 (27) [20] CDs, 18 (23) [9] BHUs and 6 (1) [2] RHCs, staff frequently (rarely) [never] took patients' history. The overall analysis of this standard shows that this standard was not achieved in most of the PHCFs of district Mansehra. According to PHC standards, the patient should be referred to other services like ultrasound tests or any other service not available at the PHC. The 15 (32) CDs, 15 (25) BHUs, and 7 (2) RHCs frequently (rarely) refer patients for other services. There were 3 out of 50 CDs that never referred any patient for other services. 
Standard 2.8: It suggests that the patient should be encouraged for a future checkup Many diseases require a proper and long-term checkup. Staff in 16 (31) CDs, 22 (27) BHUs, and 5 (4) RHCs frequently (rarely) make an appointment for a future checkup. Staff in 3 CDs and 1 BHUs never make future appointments for patients. The overall analysis of this standard shows that this standard was achieved in most of PHCFs. Similarly, standards also require staff should use previous care results in follow-up visits. Staff in 2 out of 50 CDs never uses results of previous care in a follow-up visit. Staff in 17 (31) CDs, 24 (25) BHUs, and 7 (2) RHCs frequently (rarely) use results of previous care in a follow-up visit. The overall analysis of this standard shows that this standard was achieved in most of the PHCFs of district Mansehra.

\section{Standard 2.9: National and provincial Treatment guidelines are available and used for those services listed as offered}

According to PHC standards, National/Provincial guidelines for various diseases and services should be available in PHCFs, and staff should be trained to provide these services. Table 4 shows that guidelines for VCT, STD, HIV/AIDS, FP, Delivery, ANC, IMNCI were lacking in most CDs. Overall, S.T.D., VCT, and HIV/AIDS guidelines were not available in PHCFs, and the staff was not trained to cope with these services and diseases.

Table 4: Disease awareness and guidelines followed by staff

\begin{tabular}{|c|c|c|c|c|c|c|c|c|c|c|c|c|}
\hline \multirow{3}{*}{ Disease Name } & \multicolumn{4}{|c|}{ Civil Dispensary } & \multicolumn{4}{|c|}{ Basic Health Unit } & \multicolumn{4}{|c|}{ Rural Health Center } \\
\hline & \multicolumn{2}{|c|}{$\begin{array}{l}\text { Guideline } \\
\text { available }\end{array}$} & \multicolumn{2}{|c|}{$\begin{array}{c}\text { Staff } \\
\text { Trained }\end{array}$} & \multicolumn{2}{|c|}{$\begin{array}{l}\text { Guideline } \\
\text { available }\end{array}$} & \multicolumn{2}{|c|}{$\begin{array}{c}\text { Staff } \\
\text { Trained }\end{array}$} & \multicolumn{2}{|c|}{$\begin{array}{l}\text { Guideline } \\
\text { available }\end{array}$} & \multicolumn{2}{|c|}{$\begin{array}{c}\text { Staff } \\
\text { Trained }\end{array}$} \\
\hline & Yes & No & Yes & No & Yes & No & Yes & No & Yes & No & Yes & No \\
\hline Skin Disease & 19 & 31 & 19 & 31 & 22 & 28 & 16 & 34 & 6 & 3 & 4 & 5 \\
\hline Diabetes & 24 & 26 & 24 & 26 & 33 & 17 & 23 & 27 & 6 & 3 & 4 & 5 \\
\hline Immunization & 10 & 42 & 10 & 40 & 25 & 25 & 21 & 29 & 7 & 2 & 5 & 4 \\
\hline Anemia & 28 & 22 & 27 & 23 & 27 & 23 & 22 & 28 & 7 & 2 & 3 & 6 \\
\hline VCT & 2 & 48 & 1 & 49 & 7 & 43 & 6 & 44 & 5 & 4 & 2 & 7 \\
\hline Hypertension & 42 & 8 & 42 & 8 & 46 & 4 & 34 & 16 & 7 & 2 & 6 & 3 \\
\hline ARI & 36 & 14 & 33 & 17 & 35 & 15 & 30 & 20 & 9 & 0 & 4 & 5 \\
\hline Measles & 11 & 39 & 11 & 39 & 35 & 15 & 32 & 18 & 7 & 2 & 5 & 4 \\
\hline Hepatitis & 20 & 30 & 14 & 36 & 31 & 19 & 23 & 27 & 6 & 3 & 5 & 4 \\
\hline Polio & 29 & 21 & 29 & 21 & 38 & 12 & 33 & 17 & 8 & 1 & 6 & 3 \\
\hline Diarrhea & 35 & 15 & 35 & 15 & 38 & 12 & 34 & 16 & 9 & 0 & 5 & 4 \\
\hline STD & 1 & 49 & 1 & 49 & 22 & 28 & 15 & 35 & 6 & 3 & 4 & 5 \\
\hline HIV/AIDS & 5 & 45 & 4 & 46 & 19 & 31 & 9 & 41 & 7 & 2 & 5 & 4 \\
\hline TB \& DOTS & 19 & 31 & 14 & 36 & 27 & 23 & 21 & 29 & 7 & 2 & 4 & 5 \\
\hline Malaria & 25 & 25 & 24 & 26 & 35 & 15 & 29 & 21 & 8 & 1 & 6 & 3 \\
\hline Family Planning & 5 & 45 & 5 & 45 & 32 & 18 & 28 & 22 & 9 & 0 & 6 & 3 \\
\hline PNC & 4 & 46 & 3 & 47 & 27 & 23 & 26 & 24 & 9 & 0 & 6 & 3 \\
\hline Delivery & 3 & 47 & 2 & 48 & 30 & 20 & 30 & 20 & 8 & 1 & 6 & 3 \\
\hline ANC & 3 & 47 & 3 & 47 & 32 & 18 & 30 & 20 & 9 & 0 & 7 & 2 \\
\hline IMNCI & 2 & 48 & 2 & 48 & 25 & 25 & 19 & 31 & 8 & 1 & 4 & 5 \\
\hline Minor Surgery & 31 & 19 & 26 & 24 & 34 & 16 & 34 & 16 & 7 & 2 & 5 & 4 \\
\hline Injury & 44 & 6 & 40 & 10 & 44 & 6 & 37 & 13 & 8 & 1 & 5 & 4 \\
\hline First Aid & 42 & 8 & 40 & 10 & 41 & 9 & 40 & 10 & 9 & 0 & 7 & 2 \\
\hline
\end{tabular}

Source: Based on Authors' data analysis

Standard 2.10: All children who visit the facility have their weight plotted correctly on their health card and have their immunization status checked

Regarding standard 2.10, in $3 \mathrm{CDs}, 32 \mathrm{BHUs}$, and 4 RHCs, a child under five are weighted. In most of the CDs weight machine was not available. Some BHUs weight machines were non-functional, and only $6 \% \mathrm{CDs}, 22 \% \mathrm{BHUs}$, and $89 \%$ RHCs were plotting weight on the child health card. This standard needs improvement, especially at the CDs level. It was observed that in $26 \%(14 \%)$ of CDs, $82 \%$ (78\%) BHUs and $100 \%(100 \%)$ RHCs, immunization is checked (provided to children). As far as BHUs and RHCs are concerned, this standard is achieved, but at the CDs level, immunization is not available in most of the CDs.

Additionally, in some backward areas, people, especially females, are not educated enough to understand the weight and vaccine information on child health cards. It is the 
responsibility of staff to provide the parent with sufficient information regarding vaccine and weight. It was observed during this research study that in $14 \%$ CDs, $90 \%$ BHUs, and $100 \%$ RHCs, information regarding weight and immunization is provided to parents. This standard is achieved in BHUs and RHCs but not achieved at the CDs level.

Standard 2.11: Healthcare providers regularly educate their clients on health issues in a way that is easy to understand

Standard 2.11 requires that all the PHCs should conduct four group health sessions in a month. Data collected revealed that only one BHU conducts health education sessions four times a month. There are 45 PHCs that conduct health sessions once, twice, or three times a month. On the other hand, $61 \mathrm{PHC}$ (42 CDs, $18 \mathrm{BHUs}$, and $1 \mathrm{RHC}$ ) do not conduct any health session at all. Furthermore, staff should also distribute health education material during healthcare sessions. Staff in 42 (8) CDs, 14 (26) BHUs, and 1 (7) RHC never (rarely) distributed health education material to the community/patients. Only the staff in 10 BHUs and 1 RHC frequently distributes health education material to the community/patients. The overall analysis of this standard shows that this standard was not achieved in most of the PHCFs of district Mansehra and needs improvement.

\section{Standard 2.12: Clients/Patients are given accurate information about their medication regime to enable them to manage it}

As per standard 2.12, the healthcare providers should guide the patients about the medication, the dosage of medication, what time of the day it should be taken, and how long it should be taken. This question was asked from patients, and a total of 207 responses were collected. Regarding guidance, 67\% (32\%) responses from CDs, 56\% (44\%) responses from BHUs, and $78 \%(22 \%)$ responses from RHCs highlighted that patients are frequently (rarely) guided about dosage, timings, and duration of the medicines. Only one response from CDs was that patients were never guided about dosage, timing, and medicine duration. This standard was achieved in most of the PHCFs of district Mansehra.

Likewise, service providers should ask the patients about care management and precautions. During this research, only three out of 207 responses from patients were about not understanding the message conveyed to them. Those three responses were from RHCs, where OPD is crowded and patients' time of interaction with the service provider (Doctors or Medical Technician) is very less. Overall, this standard is achieved in the PHC facilities of Mansehra.

\section{Standard 2.13: Staff follows correct aseptic techniques and washes their hands between clients/patients}

Staff in 8 (28) [14] CDs, 1 (22) [27] BHUs, and 0 (4) [5] RHCs responded that they never (rarely) [frequently] follow aseptic techniques. Reasons for not following aseptic procedures identified by the staff include the unavailability of water and aseptic solution at the CDs level. Overall, this standard was achieved at BHUs and RHCs level

\section{Standard 2.14: Rational prescribing is practised to minimize the risk of drug resistance, ensure appropriate treatment and enable cost-effective care}

This study revealed that $41 \mathrm{CDs}, 43 \mathrm{BHUs}$, and 9 RHCs have an essential drug list available. Out of these 39 CDs, 42 BHUs, and all 9 RHCs follow the essential drug list. Likewise, staff should follow guidelines for antibiotics while prescribing medicines to patients. Out of the total sample, $3 \mathrm{CDs}, 10$ BHUs, and 4 RHCs have guidelines for antibiotics available. Out of these, the staff of 2 CDs and all BHUs and RHCs follow antibiotics guidelines.

According to PHC standard 2.14, the diagnosis should be written on a prescription slip. Staff in 16 (26) CDs, 32 (15) BHUs, and 8 (1) RHCs responded that they frequently (rarely) write diagnoses on the prescription slip. Staff in $8 \mathrm{CDs}$ and 3 BHUs responded that they never write diagnoses on the prescription slip. Staff in $2 \mathrm{CDs}$ never used results of previous care in the follow-up. Staff in 31 (17) CDs, 25 (24) BHUs, and 2 (7) RHCs responded that they rarely (frequently) use results of previous care in follow-up. Overall, this standard was achieved. 


\section{Standard 2.15: Essential drugs and supplies are available at all times during open hours}

As per standard 2.15, medicine stock cards should be updated. Staff in 39 (11) CD, 43 (6) BHUs, and 8 (1) RHCs frequently (rarely) maintains stock cards. Only in one BHU staff never maintains stock cards. Overall, the stock cards were maintained in most of the facilities. Furthermore, the physical stock should match the stock mentioned in-stock cards. In 37 (12) CDs, 36 (8) BHUs and 9 RHCs physical stock frequently (rarely) match to stock cards/registers. Only in one $\mathrm{CD}$ and one BHU, the physical stock never corresponds to stock cards/registers. Overall, this standard was achieved in PHCFs of district Mansehra.

Furthermore, standard 2.15 suggests that there should be a stock of essential drugs in store. The essential stock of drugs is important to cope with any emergency. In 26 (24) CDs, 36 (14) BHUs, and 7 (2) RHCs, stock of essential drugs is available frequently (rarely). Overall, this standard was achieved in PHCFs of district Mansehra. Regarding expired drugs in the store/stock, 27 (11) CDs, 24 (6) BHUs, and 7 (2) RHCs frequently (rarely) check the expiry date of drugs kept in stock. Overall, the stock was checked in most facilities to ensure that no expired drugs were kept in stock.

\section{Standard 2.16: The cold chain for vaccines is maintained.}

According to the WHO, Cold Chain is a mechanism of storing and transporting vaccines to remote areas at recommended temperatures, from manufacturing to the point of use. During this research study, staff of PHCFs of district Mansehra was asked about cold chain procedures. It was observed that 4 out of $50 \mathrm{CDs}, 33$ out of 50 BHUs, and 8 out of 9 RHCs have cold chain procedures available. The rest of the $46 \mathrm{CDs}, 17 \mathrm{BHUs}$ and $1 \mathrm{RHC}$ do not have any Cold Chain Procedure available.

Figure 1: Cold chain availability (Based on Authors' data analysis)

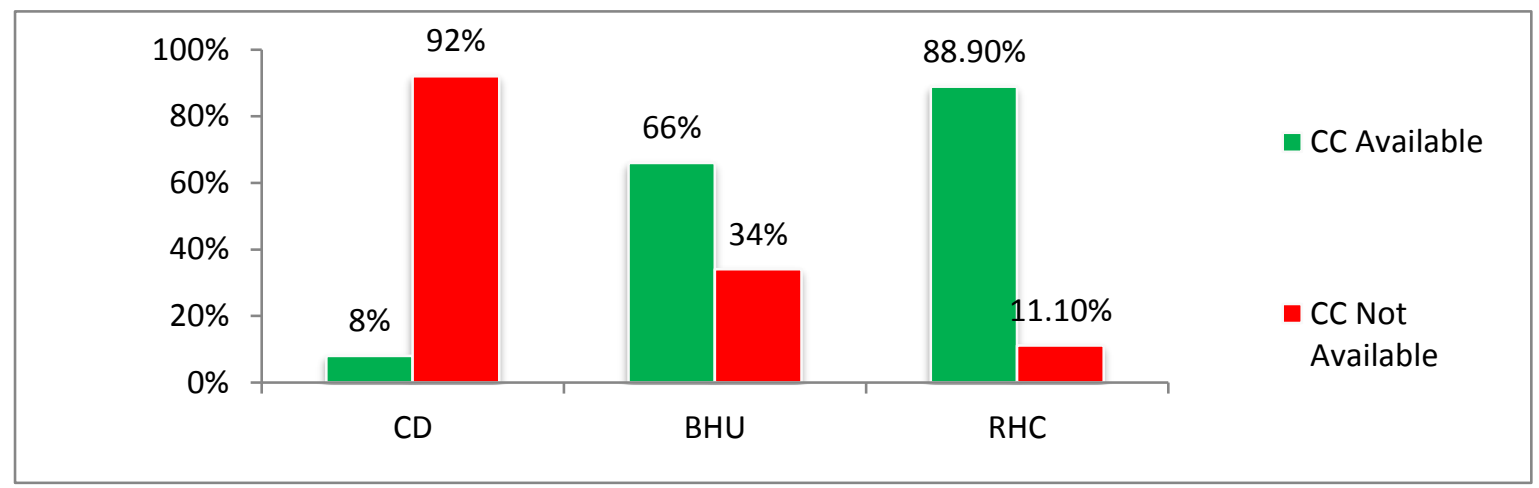

\section{Standard 2.17: Items for single-use are not reused.}

Standard 2.17 recommends that there should be some arrangement for the disposal of single-use items. Among the sample studied, 36\% CDs, $88 \%$ BHUs, and $89 \%$ RHCs have disposal systems for single-use items. This standard is not achieved at the CD level. This needs to be addressed as these single-use items can lead to communicable diseases like HIV/AIDS and cancer.

Standard 2.18: Sharps and needles are used and disposed of safely.

Regarding standard 2.18 , it was observed that $36 \%$ of sample CDs, $84 \%$ BHUs, and $89 \%$ RHCs have safety boxes available for disposing of single used items. Furthermore, this was observed that $11 \mathrm{CDs}, 5 \mathrm{BHUs}$, and 1 RHCs do not have any disposal system for needles and sharps. Apart from these 17 facilities remaining 92 facilities dispose of needles and sharps in incinerators and sharp pits. Overall, this standard was achieved in BHUs and RHCs except in CDs where only sharp pits were available, which is not that efficient as incinerator and safety boxes.

\section{Conclusion}

Using medical staff and patients' responses from 109 PHCFs on a Likert and dichotomous scale questionnaire and personal observations of PHCFs situated in district Mansehra, this study explored the on-ground facilities available at primary healthcare facilities 
in the context of primary healthcare service quality standards set by the provincial government of Khyber Pakhtunkhwa, Pakistan. A total of 207 responses from patients and 109 responses from staff were collected. Furthermore, the researcher made 109 observations. This is an applied study and has direct policy implications. Despite primary healthcare facilities, patients prefer to visit secondary and tertiary healthcare facilities, causing a severe burden on secondary and tertiary healthcare facilities. In this context, this study has identified areas of low service quality, constraints, and reasons for patients' preference for secondary and tertiary health care facilities.

The main findings of this study are that the quality of services offered at the CDs level is very low. Patients treated in CDs were not satisfied with the services. Contrarily, staff at CDs were also deprived of necessary resources to facilitate the patients. Secondly, BHUs are relatively better in terms of service provision. RHC level facilities follow most of the standards and have the capacity to meet all the primary level standards with given resources. Mostly in BHUs and RHCs, patients were satisfied with the services. If the government of Khyber Pakhtunkhwa ensures better service delivery at PHCFs, it can ultimately lessen the burden on secondary and tertiary level healthcare facilities.

The factors due to which service delivery in primary health facilities (PHCFs) was affected include cultural constraints, SOPs for referrals, transport facilities, cold chain, disposal system, patient privacy, waiting time, and display of health information posters.

- In many PHCFs, the female staff is unavailable, so patients do not visit PHC facilities due to religious or tribal restrictions. Therefore, it is recommended that government should ensure the availability of female staff in every PHC facility. It is also recommended that government also organize social awareness sessions at the community level so that most people should visit PHC facilities for basic medical needs and assistance.

- Many PHC facilities do not display posters. Necessary posters should be provided by the district headquarter from the regular budget to all PHC facilities on which detail of working hours, emergency numbers, list of services offered, and fee for providing services must be mentioned.

- A major portion of the staff in CDs (62\%), 30\% in BHUs, and 33\% in RHCs do not know the SOPs for the referral. Training sessions at the provincial and district level can help to sort out this issue.

- All of the CDs (100\%) and BHUs (98\%) and $22 \%$ of RHC do not have any transport facility to send their referred patients to higher level (secondary and tertiary) facilities. This parameter needs attention at the policy-making level as the huge capital cost is involved.

- The waiting time for the patients is more than an hour in $33.3 \%$ of RHCs. This is mainly due to the shortage of human resources and the excess of patients at the RHC level. Rationalization of staff can sort out this issue.

- Forty percent of CDs do not have any arrangements to ensure patients' privacy. By providing examination screens and one female staff at the CDs level, patients' privacy can be kept.

- Almost all CDs (94\%) do not have weight machines due to which children under five years of age are suffering. Weight machines can be provided at the CDs level.

- Cold chain for vaccines is not available in $92 \%$ of CDs. Ice line refrigerators can be provided along with human resources for vaccination purposes.

- Sixty-four percent of CDs do not have a waste disposal system for waste and single-use items. Needle cutters can be provided at the CD level by the district headquarters from the annual budget.

- Most CDs (84\%) and a relatively small percentage of BHUs (36\%) and RHCs (11\%) never conduct any health session. Social health education sessions should be conducted at the school and community levels.

\section{References}

Alhassan, R. K., Duku, S. O., Janssens, W., Nketiah-Amponsah, E., Spieker, N., Van Ostenberg, P., Arhinful, D. K., Pradhan, M., \& Rinke De Wit, T. F. (2015). Comparison of perceived and technical healthcare quality in primary health facilities: Implications for a sustainable National Health Insurance Scheme in Ghana. PLOS ONE, 10(10), 1-19. https://doi.org/10.1371/journal.pone.0140109 
Belintxon, M., Dogra, N., McGee, P., Pumar-Mendez, M. J., \& Lopez-Dicastillo, O. (2020). Encounters between children's nurses and culturally diverse parents in primary health care. Nursing \& Health Sciences, 22(2), 273-282. https://doi.org/https://doi.org/10.1111/nhs.12683

Halcomb, E., Williams, A., Ashley, C., McInnes, S., Stephen, C., Calma, K., \& James, S. (2020). The support needs of Australian primary health care nurses during the COVID19 pandemic. Journal of Nursing Management, 28(7), 1553-1560. https://doi.org/https://doi.org/10.1111/jonm.13108

Martin-Iguacel, R., Pedersen, C., Llibre, J. M., Søndergaard, J., Jensen, J., Omland, L. H., Johansen, I. S., Obel, N., \& Rasmussen, L. D. (2019). Primary health care: an opportunity for early identification of people living with undiagnosed HIV infection. HIV Medicine, 20(6), 404-417. https://doi.org/https://doi.org/10.1111/hiv.12735

Mečev, D., \& Kardum Goleš, I. (2015). Primary healthcare service quality measurement: SERVQUAL Scale. Review of Contemporary Entrepreneurship, Business, and Economic Issues, 28(1), 161-177.

Mohammed, K., Nolan, M. B., Rajjo, T., Shah, N. D., Prokop, L. J., Varkey, P., \& Murad, M. H. (2016). Creating a patient-centered health care delivery system: A systematic review of health care quality from the patient perspective. American Journal of Medical Quality, 31(1), 12-21. https://doi.org/10.1177/1062860614545124

Nizar, H., \& Chagani, P. (2016). Analysis of health care delivery system in Pakistan and Singapore. International Journal of Nursing Education, 8(2), 21. https://doi.org/10.5958/0974-9357.2016.00041.6

Russell, K., Manias, E., \& Nicholson, P. (2021). What influences rural women's choices in maternity care: A qualitative exploratory study. Nursing \& Health Sciences, 23(4), 825833. https://doi.org/https://doi.org/10.1111/nhs.12867

Shabbir, A., Malik, S. A., \& Malik, S. A. (2016). Measuring patients' healthcare service quality perceptions, satisfaction, and loyalty in public and private sector hospitals in Pakistan. International Journal of Quality and Reliability Management, 33(5), 538-557. https://doi.org/10.1108/IJQRM-06-2014-0074

Suphanchaimat, R., Kantamaturapoj, K., Putthasri, W., \& Prakongsai, P. (2015). Challenges in the provision of healthcare services for migrants: A systematic review through providers' lens. BMC Health Services Research, 15(1), 1-14. https://doi.org/10.1186/s12913-015-1065-z

Ugo, O., Ezinne, E.-A., Modupe, O., Nicole, S., Winifred, E., \& Kelechi, O. (2016). Improving quality of care in primary health care facilities in rural Nigeria. Health Services Research and Managerial Epidemiology, 3, 1-6. https://doi.org/10.1177/2333392816662581

Worthington, R. P., \& Gogne, A. (2011). Cultural aspects of primary healthcare in India: A case-based analysis. Asia Pacific Family Medicine, 10(1), 1-5. https://doi.org/10.1186/1447-056X-10-8

Yohana, J. M., Enoch, S., Vincent, S., Mpho, C., Maureen, B., \& Amos, Y. M. (2016). Availability of guidelines and policy documents for enhancing performance of practitioners at the Primary Health Care (PHC) facilities in Gaborone, Tlokweng and Mogoditshane, Republic of Botswana. Journal of Public Health and Epidemiology, 8(8), 127-135. https://doi.org/10.5897/jphe2016.0812

Zheng, X., Xiong, Y., Ye, J., Deng, Z., \& Zhang, X. (2013). Analysis of government investment in primary healthcare institutions to promote equity during the three-year health reform program in China. BMC Health Services Research, 13(1), 1-6. https://doi.org/10.1186/1472-6963-13-114 